\title{
Condenados pela primeira página: problematizando as relações entre jornalismo, ética e verdade ${ }^{1}$
}

\section{Rafael Fortes}

\section{Resumo}

Dentre os tipos de produção midiática, o jornalismo se destaca pelo vínculo que, em tese, estabelece com a verdade, o que lhe confere notável poder, inserção e legitimação social. Partindo de uma discussão sobre o teor da pauta da mídia corporativa brasileira (FONTES, 2008), este artigo analisa um episódio: a "notícia" de capa do Jornal do Brasil (15 maio 2007) informando que traficantes utilizam o sítio de relacionamentos Orkut para fazer apologia do crime e exibir armas. No dia seguinte, "descobriu-se" que, na verdade, as fotografias mostravam jovens atores durante a gravação de um filme policial. Longe de constituir um caso isolado, o ocorrido é típico e ajuda a lançar luz sobre aspectos relativos às rotinas produtivas e à linha editorial da mídia corporativa, como 0 fato de em momento algum o jornal ter admitido que "mentiu". 0 trabalho também aborda implicações éticas e políticas de tal prática jornalística.

\section{Palavras-chave}

Jornalismo. Ética. Jornal do Brasil. Juventude. Violência.

Rafael Fortes | raffortes@hotmail.com

Doutor em Comunicação pela Universidade Federal Fluminense (UFF). Professor da Universidade Federal do Estado do Rio de Janeiro (UNIRIO). Organizou o livro Segurança Pública, Direitos Humanos e Violência.

\section{Introdução}

Trata-se de não mentir - e de não deixar mentir (BUCCl, 2000, p. 51)

No caso da violência, percebe-se que o grupo social mais vitimizado é a-quele socialmente excluído da festa do consumo, desprovido dos símbo-los que caracterizam o 'cidadão de bem', revestido pelos signos da pobreza, como ser jovem, negro e morar em morro ou periferia da cidade, sendo identificado como bandido (NJAlNE et al., 1997).

Nos meses recentes, o Supremo Tribunal Federal (STF) decidiu sobre duas leis relativas ao jornalismo: revogou a Lei de Imprensa e a lei que determinava a obrigatoriedade de diploma universitário específico para o exercício da profissão. Independentemente das divergências e pontos de vista a respeito de cada uma das medidas, é positivo o fato de se gerar um debate em torno do setor de atividade profissional que submete os demais a escrutínio (em outras palavras, sobre 0 setor da sociedade que se permite falar, criticar, denunciar etc. todos os demais), mas raramente se debruça sobre si mesmo, seus problemas, incoerências e mazelas 
- que dirá aceitar que outros o façam (BUCCI, 2000, p. 37-55).

Este artigo discute alguns aspectos relativos ao jornalismo tal qual realizado nos meios de comunicação hegemônicos no Brasil. 0 enfoque temático diz respeito à violência urbana no Rio de Janeiro - tema, aliás, bastante pautado pelos veículos sediados na cidade, e mesmo pelos de fora. Tal abordagem se insere em um contexto no qual a cobertura realizada pelo jornalismo corporativo com frequência opta pela espetacularização e tem caráter episódico e descontextualizado (ARBEX JÚNIOR, 2003). No caso do Rio de Janeiro, problemas graves como os mais de mil assassinatos cometidos anualmente pela polícia (considerando apenas dados oficiais) e registrados sob a rubrica "autos de resistência" raramente são apresentados e problematizados. Observa-se 0 crescimento, nos anos recentes, de formas de violência aberta, praticadas com apoio explícito ou velado por parte de autoridades que dirigem o Estado. Sob a capa de "uma certa 'normalidade", ações truculentas por parte do aparelho coercitivo do Estado se dão de forma cotidiana e, ao mesmo tempo, silenciosa. A violência é rotineira, mas só chega às manchetes excepcionalmente (FONTES, 2008, p. 146-147). Cabe lembrar que, não raro, estas ações são apoiadas pelos meios de comunicação corporativos e amplos setores da sociedade (inclusive pelo público destes veículos), como na Chacina do Alemão ocorrida em junho de 2007 e celebrada sob o nomefantasia "mega-operação policial" (FORTES, 2008).

Mais especificamente, debruçamo-nos sobre um caso específico, que envolve: a) uma denúncia realizada pelo Jormal do Brasil de que traficantes de drogas exibiam armas e praticavam apologia do crime pela internet, através do sítio de relacionamentos Orkut; b) a postura do veículo no dia seguinte à veiculação da denúncia, que se mostrou em grande parte equivocada: o periódico inventou novas mentiras, em vez de retratar-se.

0 artigo começa com uma breve descrição e análise do estudo de caso. Em seguida, aborda aspectos importantes para situar o jornalismo, como: concentração de propriedade e falta de pluralidade na mídia corporativa; condições de trabalho nas redações; e ética. A terceira seção conta com contribuições de pesquisadores das ciências humanas para a discussão e compreensão da violência urbana e de sua relação com os meios de comunicação.

\section{Condenados pela primeira página ${ }^{2}$}

Na tarde de 15 de maio de 2007, Extra Online informou: um jornal carioca publicou em sua primeira página, na edição de hoje, uma foto de 
atores do filme Cidade dos Homens, ainda inédito, como sendo traficantes exibindo seu poder de fogo'."'3 A nota continha uma declaração preocupada e indignada, atribuída a um dos atores retratados como traficantes, mas não informa que órgão de imprensa veiculara a imagem. Tratava-se do Jornal do Brasil, que trouxe na capa 0 quadro que aparece na figura 1 (as figuras reproduzindo o material do $J B$ estão nos anexos ao final do artigo).

0 título de uma matéria publicada no sítio Comunique-se, na mesma tarde, afirmava categoricamente: "Matéria do JB confunde atores com traficantes". ${ }^{4}$ Erros deste tipo

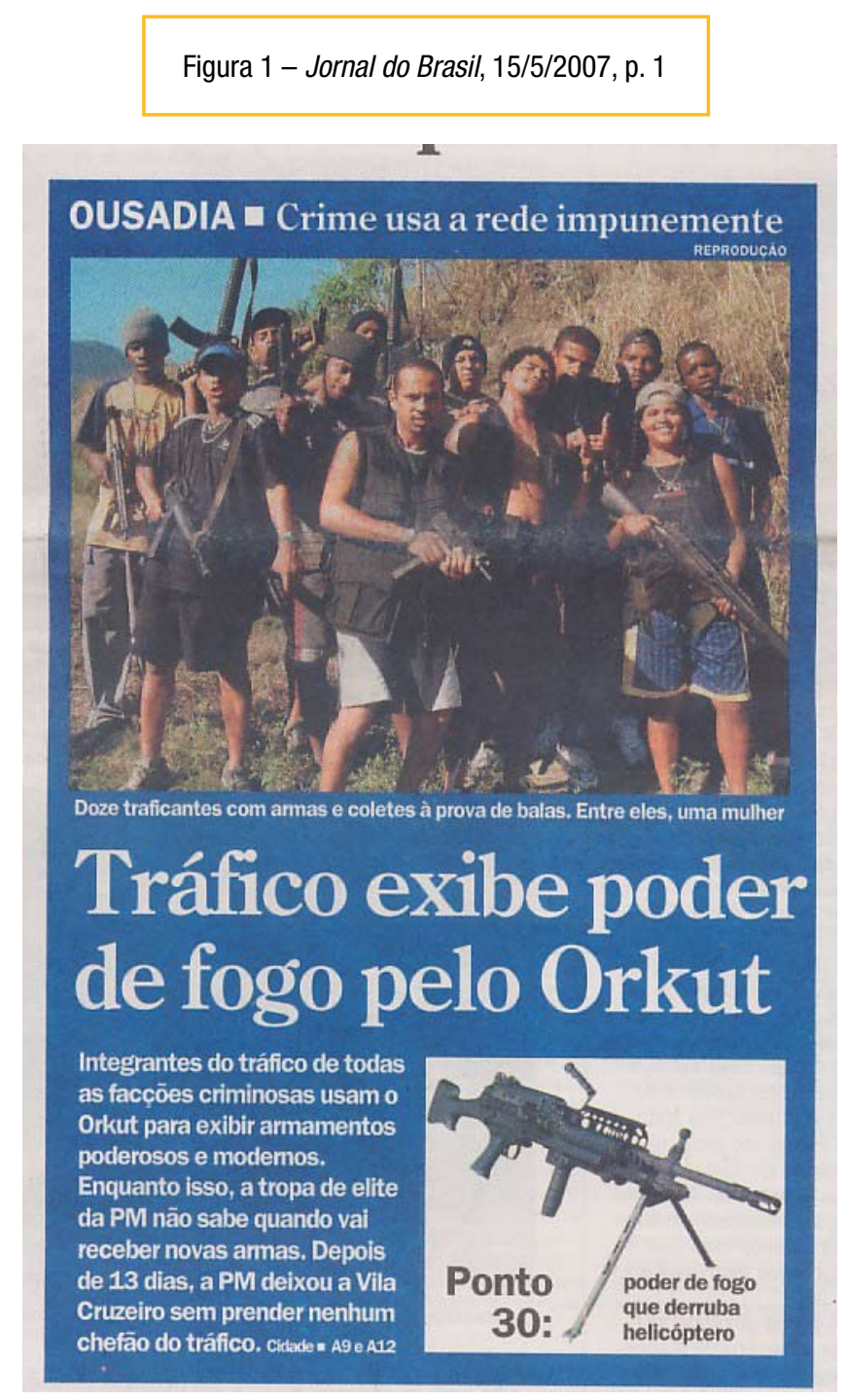

A nota encontrava-se no endereço http://extra.globo.com/lazer/retratosDaVida/\#58251. Não está mais no ar. Acesso em: 3 jun 2009.

A "reportagem" do Jornal do Brasil: 'Traficantes exibem arsenal de guerra em site na internet". Jornal do Brasil, 15 mai 2007. Disponível em: <http://jbonline.terra.com.br/editorias/rio/papel/2007/05/15/rio20070515004.html>. Aces-so em: 3 jun. 2009. 
podem ocorrer diariamente no jornalismo.

A diferença é que, muitas vezes, os leitores, ouvintes e espectadores sequer ficam sabendo do ocorrido, pois os veículos jornalísticos não os informam sobre os erros nem fazem as correções devidas - em geral, os concorrentes também silenciam. ${ }^{5}$ Isso acontece, por exemplo, quando jovens assassinados pela polícia na periferia de grandes cidades brasileiras aparecem nas páginas policiais como bandidos - na maioria dos casos, sem terem sequer passagem pela polícia. A prática é corriqueira e, no caso de São Paulo, foi denunciada e amplamente documentada, por exemplo, no livro Rota 66, do jornalista Caco Barcellos, lançado no início da década de 1990. Até hoje boa parte da cobertura policial realizada pela mídia corporativa segue não apenas ignorando as denúncias presentes na obra - um sucesso de vendas - o que já seria bastante grave, mas fazendo pior: repetindo as mesmas práticas.

Athayde, Bill e Soares (2005) discutem a questão dos estigmas e preconceitos lançados sobre os jovens moradores das comunidades pobres do Rio de Janeiro e o impacto sobre a auto-estima destes. A reflexão dos autores permite a formulação de questões quanto ao caso: se os atores tivessem pele clara, cabelo liso e olhos claros, a verossimilhança da foto para os profissionais por quem ela passou até sair na primeira página teria sido a mesma? Ou alguém teria desconfiado da "realidade" exposta? Que lugar ocupam - em nossas ideias, preconceitos e certezas - os jovens de pele escura, sexo masculino e pobres?

Constatado o erro e sabendo-se que houve acaloradas discussões na redação durante a tarde do dia 15 , faltava aguardar a capa e as explicações do dia seguinte. 0 erro foi assumido? Não. Houve retratação?

Não ${ }^{6}$ Houve pedido de desculpa às vítimas? Não. Houve publicação de direito de resposta e/ou de correção do erro em espaço editorial equivalente àquele utilizado para divulgá-lo? Não.

Se fosse só isso, já seria grave. Mas o Jornal do Brasil foi além, como se percebe analisando o quadro que compõe a figura 2. Primeiro, o jornal publica novamente a foto - e duas vezes. Mesmo considerando que ela está inserida no contexto em que aparece na internet, trata-se de uma atitude no mínimo

As publicações do Jornal do Brasil tiveram alguma repercussão em espaços como o portal Comunique-se, Observa-tório da Imprensa e alguns blogues. Raras notas foram divulgadas em endereços eletrônicos da concorrência, mas sem especificar dados essenciais como o nome do veículo que cometeu a barriga (notícia errada ou falsa, no jargão das redações). Malgrado a apologia da "concorrência" como uma das características essenciais do capitalismo, os veículos da mídia hegemônica raramente criticam-se entre si ou apontam falhas alheias.

A matéria do Comunique-se mencionada anteriormente cita a preocupação do diretor do grupo teatral Nós do Morro, ao qual pelo menos um dos jovens atores era vinculado, de exigir retratação do jornal. 


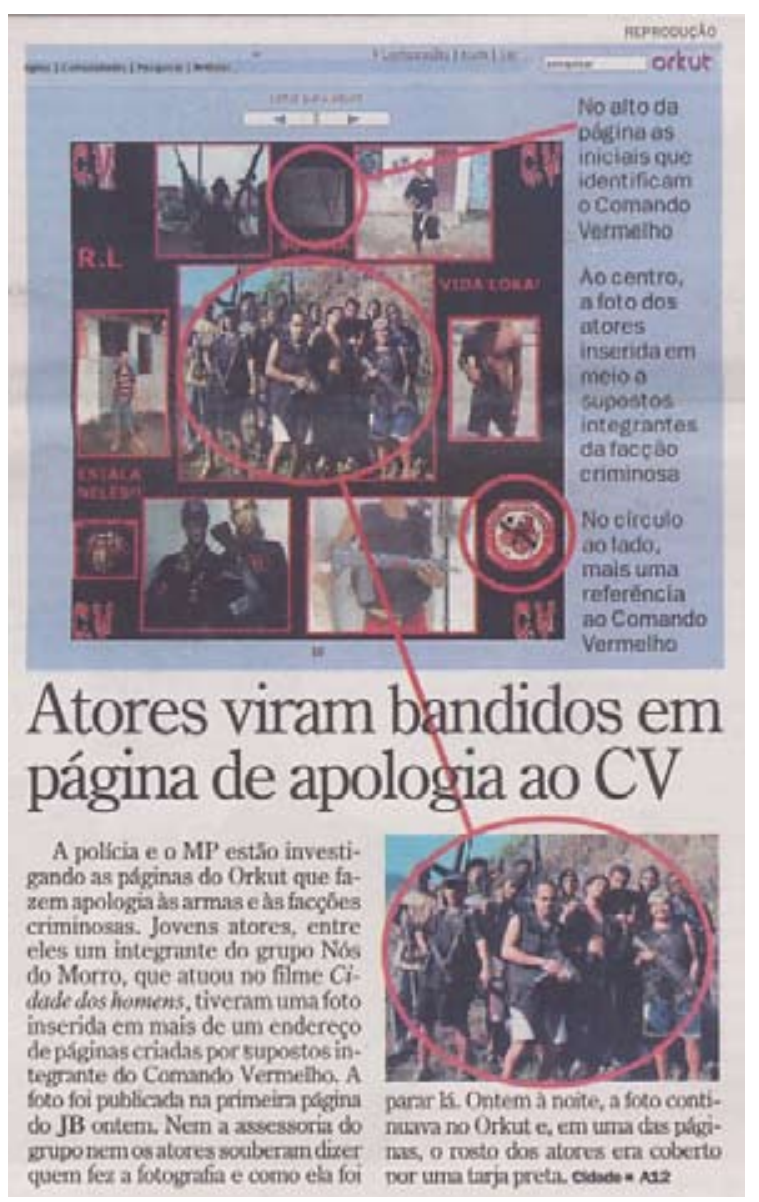

discutível, se pensarmos em relação à

questão dos estigmas e à maneira como é

feita a leitura de imagens - muitas vezes

menos racional e atenta que a de textos. ${ }^{7}$

Salta aos olhos o título: "Atores viram bandidos em

página de apologia do CV". Um leitor que não tenha visto o jornal na véspera não é informado de que os atores viraram bandidos também na primeira página do Jornal do Brasil, cuja visibilidade e impacto negativos para a imagem dos jovens retratados provavelmente é muito maior. ${ }^{8}$ Embora o $J B$ insinue o contrário, internet e jornalismo

Discorrendo sobre 0 uso da imagem pelo telejornalismo, Eugênio Bucci (2000, p. 144) afirma: "convertidas em estereótipos, pressionam o discurso jornalístico por um maniqueísmo acrítico e, no limite, não informativo, apenas emocionante". Isso ocorre de forma acentuada no telejornalismo, mas também se aplica aos veículos impressos. A associação com o texto é fundamental para a apreensão imagética: "no campo do jornalismo, somente as palavras podem processar o pensamento crítico sobre a imagem. As palavras é que criam mediações entre o que se vê e o que se compreende daquilo que é visto" (BUCCI, 2000, p. 144). Portanto, tal uso de imagens na capa tem claro objetivo de espetacularizar a informação e de direcionar a leitura de forma única e maniqueísta.

Jornal não é lido só por quem compra em banca ou assina. Muitos olham na banca. Inclusive um dos atores teria descoberto assim a "notícia". 
não são a mesma coisa. Atores aparecerem como traficantes no Orkut é algo grave, assim como o é 0 delito de apologia ao crime. Entretanto, mais grave é serem apresentados como bandidos na primeira página de um jornal. Ora, no Orkut e em outros espaços da internet, qualquer um com acesso à rede e conhecimento de programas de informática pode se fazer passar por outrem, veicular informações falsas, editar fotos e atribuir a outras pessoas palavras, atos e situações. Tratase, portanto, de universo em que muitos usam e abusam da liberdade e anonimato que 0 meio lhes proporciona. Excessos e crimes podem e devem ser investigados pela polícia e julgados pelo judiciário, não obstante a dificuldade de reunir provas e identificar suspeitos. 0 jornalismo, por outro lado, pode ser definido de forma breve como uma atividade que se responsabiliza por informar às pessoas o que acontece. É uma prática profissional socialmente aceita $\mathrm{e}$ dotada de credibilidade e importante para a democracia. Portanto, a informação encontrada em um endereço qualquer da internet e a informação veiculada na primeira página de um jornal, por definição (e por várias razões), não são a mesma coisa, nem gozam (ou deveriam gozar) do mesmo valor. Ao, de maneira enviesada, igualar-se ao Orkut, $0 J B$ permite que o leitor considere que qualquer coisa veiculada na internet possa ir parar na primeira página do jornal, com status de verdade. Ao igualar jornalismo e Orkut, o jornal se anula enquanto tal.

Observe-se 0 trecho a seguir, retirado da matéria que aparece na figura 3 :

Figura 3 - Jornal do Brasil, 16/5/2007, p. A12.

TRAFICO = Em paiginas no site de relacionamentos, supostos traficantes exibem ammamentos Polícia investiga arsenal no Orkut

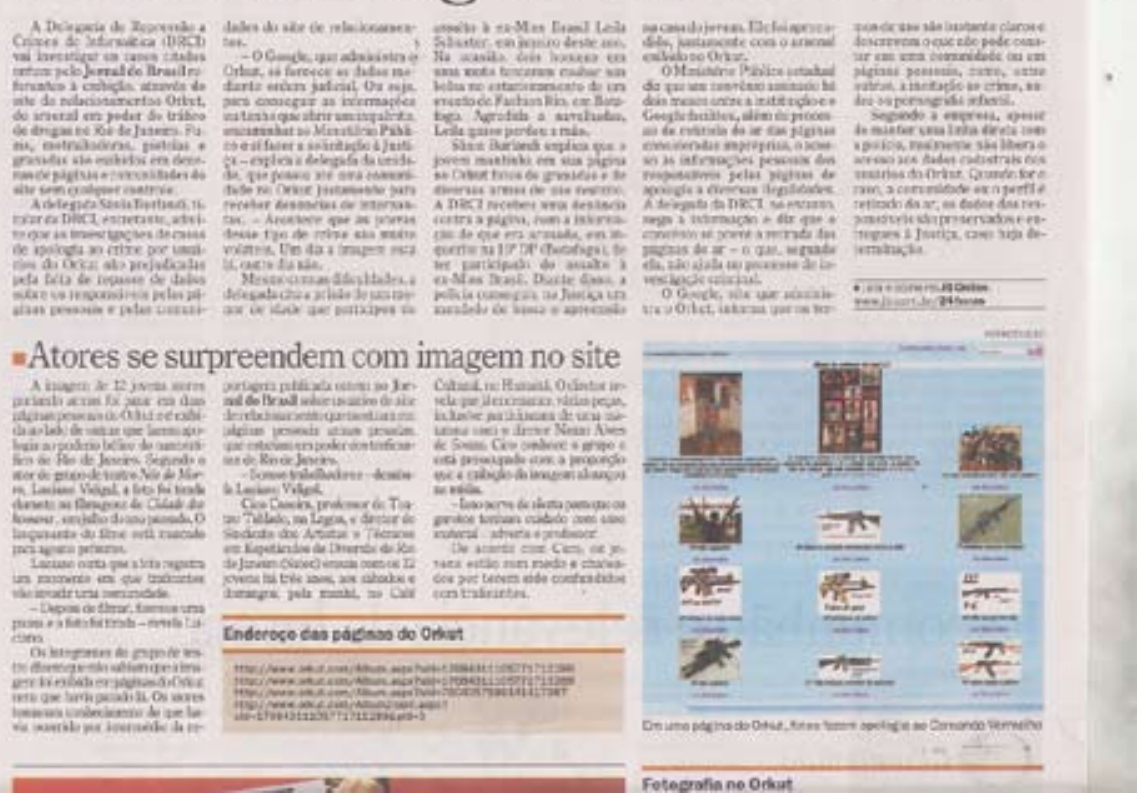


Os integrantes do grupo de teatro dizem que não sabiam que a imagem foi exibida em páginas do Orkut nem que havia parado lá. Os atores tomaram conhecimento do que havia ocorrido por intermédio da reportagem publicada ontem no Jornal do Brasil sobre usuários do site de relacionamento que mostram em páginas pessoais armas pesadas, que estariam em poder dos traficantes do Rio de Janeiro.

0 trecho contém ao menos três falácias.

Primeiro, posar de serviço de utilidade pública. Dizer que os atores foram informados do ocorrido pelo jornal é mentira, por duas razões: a) os atores não "tomaram conhecimendo do que havia ocorrido por intermédio da reportagem", e seria impossível que isto acontecesse, pois nela não se desmascarou confusão alguma: os atores eram traficantes; b) a reportagem não só não informou sobre a confusão, mas fez parte desta e ajudou a disseminá-la. Na verdade, segundo a matéria do sítio Comunique-se citada anteriormente, a história veio à tona quando um dos atores surpreendeu-se ao aproximar-se de uma banca de jornal e ver sua foto estampada na primeira página. $\mathrm{Ou}$ seja, o título "Atores se surpreendem com imagem no site" é igualmente mentiroso.

Segundo, dizer que a matéria da véspera versava "sobre usuários do site de relacionamento que mostram em páginas pessoais armas pesadas". Eis os títulos e legenda publicados um dia antes: "OUSADIA

- Crime usa a rede impunemente"; "Doze traficantes com armas e coletes à prova de balas. Entre eles, uma mulher"; "Tráfico exibe poder de fogo pelo Orkut" (ver figura 1). 0 veículo mente sobre o que ele mesmo publicou na véspera.

Terceiro, usar o futuro do pretérito. Com isso, o jornal joga para o terreno da hipótese e da dúvida o que noticiara como verdade e certeza. Publicou-se inclusive um quadro intitulado "Versões sobre a foto" (figura 4). 0 tom usado para dizer que atores, produção do filme e assessoria de imprensa não sabem informar quando e por quem as fotos foram feitas e como foram parar no Orkut se aproxima de uma insinuação de culpar as vítimas. Culpar a vítima, ainda mais quando esta "não sabe se explicar", é uma prática tão nefasta quanto comum em nossa sociedade (ver a terceira seção deste artigo). ${ }^{9}$ Um certo tipo de jornalismo contribui para manter e reforçar esta lógica: viola uma série de preceitos legais, entre os quais está um básico: todos são inocentes até que se prove o contrário. Trata-se de mais um exemplo de uma norma jurídica que rege as relações sociais (Constituição Federal, art. $5^{\circ}$. inciso 
Figura 4 - Jornal do Brasl, 16/5/2007, p. A12.

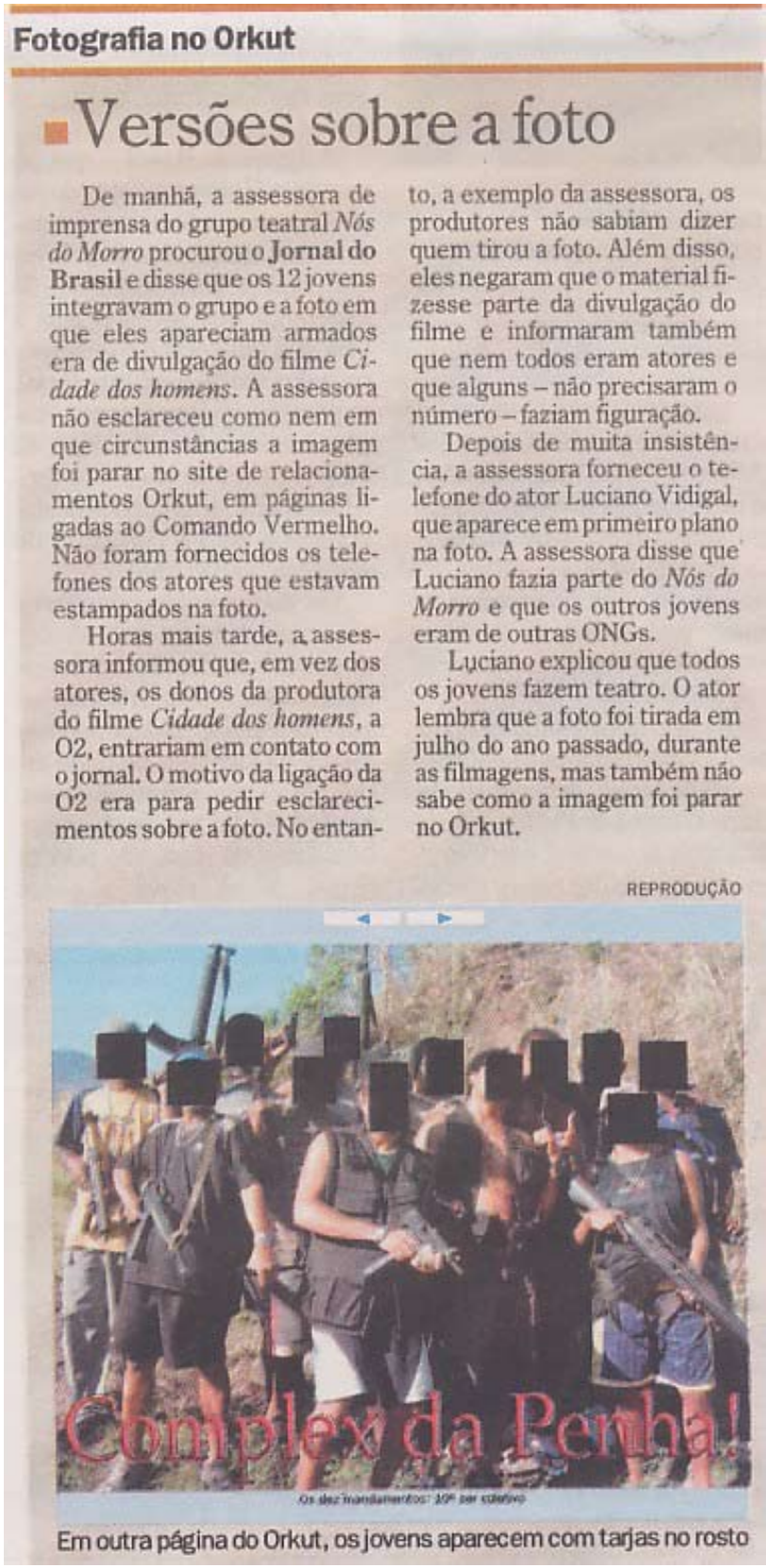

LVII) ${ }^{10}$ mas é ignorada com frequência pela mídia corporativa, que se considera acima de leis e instituições (em nome da "liberdade de imprensa"). Discutir os possíveis caminhos percorridos pela foto de um dia de gravação até 0 Orkut parece uma tática tergiversante,

10 Onde se lê: "Art. $5^{\circ}$ Todos são iguais perante a lei, sem distinção de qualquer natureza, garantindo-se aos brasileiros e aos estrangeiros residentes no País a inviolabilidade do direito à vida, à liberdade, à igualdade, à segurança e à propriedade, nos termos seguintes: [...] LVII - ninguém será considerado culpado até o trânsito em julgado de sen-tença penal condenatória" (CONSTITUIÇÃO, 1988). 
desviando a atenção do problema principal.

Qualquer que tenha sido o percurso, trata-se de aspecto relevante para a discussão central aquela que $0 J B$ se recusou a travar.

\section{3 Ética e jornalismo na mídia corporativa}

Não estamos falando de um jornalismo ideal ou abstrato, mas praticado em meio a uma lógica pautada pelo espetáculo (BUCCI, 2000), pela concentração de meios e pela desigualdade no acesso, produção e circulação de conteúdos (MORAES, 2009). No Brasil, ele é praticado em um contexto de pouca regulamentação, pouca aplicação das leis existentes e insistente esforço dos órgãos e entidades patronais para revogá-las ou torná-las letra morta. ${ }^{11}$ A mídia corporativa se coloca acima da sociedade e da lei: qualquer proposta de regulação é imediatamente classificada como "censura" e refutada. Mesmo normas importantes para garantir um mínimo de democracia e equidade nas manifestações midiáticas, como o direito de resposta, raramente se cumprem.
Trata-se de um jornalismo de mercado, submetido a um processo de "concentração da informação nas mãos de empresas monopolizadoras", que leva a um quadro em que "convergem dois monopólios: do direito a produzir informação, concentrado nas mãos das grandes empresas que formam a indústria dos meios de comunicação; e 0 do direito a ser a voz autorizada a proferir o discurso da informação", exercido pelos jornalistas (ENNE, 2007, p. 77-78). A discussão raramente parte do pressuposto básico: 0 direito à comunicação. ${ }^{12} 0$ fundamento da atividade jornalística é o direito do cidadão à informação e à comunicação, e não o mercado - este "é consequência" (BUCCI, 2000, p. 33). ${ }^{13}$

Para Enne (2007, p. 78), "a informação veiculada nas mega empresas de comunicação, em geral, não visa à promoção da transformação social e à formação de uma consciente esfera pública, nem a dar voz aos múltiplos sujeitos sociais, evitando, assim, a concentração do direito de significar nas mãos de poucos".

Essa concentração produz uma série de efeitos negativos e está na raiz de episódios como 0 analisado neste artigo. Somada à existência

Isto aconteceu, por exemplo, com o projeto de criação do Conselho Federal de Jornalismo (CFJ), um órgão de pares ao qual seriam atribuídas uma série de tarefas, incluindo a possibilidade de abertura e julgamento de processos por parte de uma comissão de ética, tal como ocorre em profissões como medicina e direito. Enviado ao Congresso no primeiro mandato do governo Lula, foi bombardeado pesadamente pela mídia corporativa e rapidamente engavetado. Outro exemplo é a defesa da anulação da Lei de Imprensa, sem elaboração de qualquer dispositivo para substituí-la (REVOGAÇÃo, 2009).

Cabe ressaltar que a ideia de direito à comunicação é diferente de um suposto direito a ser informado exclusivamente pelo jornalista ou pelo jornalismo da mídia corporativa.

Na medida em que se encontram inseridas numa sociedade capitalista, as empresas de comunicação, como quaisquer outras, necessitam de receita para se manter. Esta característica específica - vender um produto ao público e aos anunciantes - diz respeito às condições materiais de existência do negócio do jornalismo. Este não necessariamente se confunde com a defesa, nas pautas, dos interesses de empresas e do mercado. 
de oligopólios, contribui para a veiculação

de mentiras e manipulaçã $0^{14}$

(BUCCI, 2000, p. 138).

0 caráter problemático deste cenário fica mais nítido se recordarmos que, como afirma Bucci (2000, p. 120), "a democracia exige a pluralidade dos veículos informativos no espaço público, exige a diversidade de pontos de vista e de opiniões - os conglomerados tendem à concentração de capital e de poder". Contudo, no processo industrial de fabricação de notícias pautado pela lógica de mercado, "notícia é aquilo que vende jornal" (BUCCI, 2000, p. 182).

As condições de trabalho facilitam a ocorrência de erros. Repórteres e, principalmente, chefias tomam decisões difíceis de forma solitária, em função da pressão do tempo (BUCCI, 2000, p. 45). 0 tempo escasso e as rotinas profissionais nas redações sem dúvida ajudam a explicar 0 erro cometido no primeiro dia. ${ }^{15}$ Contudo, cabe ponderar: por que o mesmo foi ocultado no dia seguinte? Para Bucci (2000, p. 210), "a disposição para reconhecer e corrigir as falhas é um mandamento sagrado da ética jornalística". A raridade com que os veículos reconhecem e corrigem erros mostra a gravidade da situação. ${ }^{16}$
Estas observações têm 0 objetivo de situar minimamente 0 contexto em que se pratica 0 jornalismo na mídia corporativa. Ele não se pratica em abstrato, mas inserido na sociedade a que pertence. Para Bucci (2000, p. 35), "o problema ético é um problema estrutural e sistêmico". Diz respeito a jornalista, sociedade e empresas. Estas últimas precisam ser incluídas na discussão, que muitas vezes fica restrita às posturas e escolhas dos jornalistas, como se estes não trabalhassem de forma livre e sem constrangimentos de diversas naturezas. Contudo, como inexistem mecanismos de controle social e de aplicação, os códigos de ética das empresas e das entidades de classe limitam-se, na prática, a cartas de boas intenções. Esta relação traz implicações do ponto de vista macro: "[...] o jornalismo como um ambiente profissional só pode desenvolver sua ética na relação com os outros, com outros campos profissionais e sociais, com outras pessoas, outros ofícios e, finalmente, com outras formas de busca de verdades" (BUCCI, 2000, p. 55). No que diz respeito à universidade, espaço privilegiado de "busca de verdades", é notória a preferência da imprensa por pesquisas nas áreas da saúde e biológica, ao passo que os pesquisadores de ciências humanas voltados para assuntos

Definida por Bucci como “distorção deliberada da informação” (2000, p. 176).

A propósito, concordo com Dênis de Moraes quando ele aponta o equívoco de se confundir um modelo (específico) de jornalismo (em vigor nas principais empresas do ramo no Brasil) com o jornalismo em si. Nem estou genera-lizando a crítica a todos os profissionais que trabalham na mídia corporativa. Afinal, "não podemos esquecer que, entre os jornalistas da grande imprensa, existem aqueles que tentam explorar brechas, fissuras e fendas dentro dos próprios aparatos" (MORAES, 2009, p. 22).

A simples observação empírica do noticiário das corporações de mídia corrobora esta afirmação. 
como violência e segurança pública, por exemplo, têm pouca entrada na cobertura diária de tais temas. Ainda mais reduzida é a presença, na mídia hegemônica, de professores e pesquisadores de comunicação social. ${ }^{17}$

Quanto à forma, publica-se uma verdade apresentada como única e absoluta, sem que se saiba os caminhos e fundamentos que levaram a ela (BUCCI, 2000, p. 53). Tal postura combina-se à crença inabalável na noção de verdade - dura, concreta, unívoca-dos fatos costumeiramente professada pelos veículos. Isto não se dá no sentido de apreender a realidade como princípio fundador e existente a partir do qual se elabora um conhecimento - histórico, por exemplo (GINZBURG, 2008), mas de encará-la como algo que está lá, nítida, evidente e imediatamente apreensível de forma igual para todos, cabendo ao jornalista apenas desvendá-la (quase no sentido de desvelá-la). Como resultado prático, conferese caráter absoluto ao que é dito pelos veículos e abre-se pouca ou nenhuma margem para dissonâncias, divergências, incoerências, dúvidas e ambiguidades. Apresenta-se ao leitor, como se fosse neutro, um mundo unidirecional e estruturado por posições políticas. Isto nos remete ao papel estratégico desempenhado pela mídia corporativa na manutenção da ordem social (FONTES, 2008, p. 149). Sem discordar do papel fundamental da escola enquanto instância de produção da "pedagogia da hegemonia" que serve às classes dominantes (NEVES; SANT'ANNA, 2005, p. 27), proponho pensar o papel desempenhado pelos meios de comunicação enquanto aparelhos que contribuem para 0 estabelecimento de consensos e para a propagação das visões de mundo destas classes - especialmente no Brasil, onde letramento e hábitos de leitura não fazem parte do cotidiano de amplas parcelas da sociedade, e os meios de comunicação de amplo alcance popular (rádio e televisão) encontram-se concentrados nas mãos de poucos grupos, quase todos alinhados ao poder econômico. ${ }^{18}$

Entre as táticas para a construção de consenso, a hegemonia se combina também com formas de violência, incluindo a simbólica. Neste sentido, podemos considerar os meios de comunicação corporativos como parte tanto da construção de hegemonia quanto de violência simbólica (FONTES, 2008, p. 145; ARBEX

Esta observação provém de observação empírica do jornalismo corporativo realizada por mim.

Se considerarmos os projetos de utilização dos veículos na aprendizagem realizada nas salas de aula públicas e privadas, podemos perceber melhor as múltiplas linhas de atuação na esfera social, em busca da formação de consen-sos. Exemplo: em fins de abril de 2009, o Ministério Público paulista instaurou inquérito para investigar o contrato pelo qual o Governo do Estado de São Paulo comprou 220 mil assinaturas anuais da revista Nova Escola, publicada pela Editora Abril, para utilização em sala de aula (PRAZERES, 2009). 
JÚNIOR, 2003, p. 386). 0 reconhecimento proporcionado pela imagem é um dos fatores que a fazem tão importante atualmente (MARTÍN-BARBER0, 2008, p. 23). Os meios de comunicação, que poderiam trabalhar no sentido de ajudar os cidadãos a "formar cidade" (MARTÍN-BARBER0, 2008, p. 18-19) e a percebê-la, aprofundam a dicotomia trágica à qual a população pobre e seus problemas estão condenados: os regimes de invisibilidade ou de visibilidade seletiva, negativa e reforçadora de estigmas. No regime hegemônico da mídia corporativa, os jovens de pele escura e classe trabalhadora aparecem predominantemente como ameaça potencial ou concreta.

Ao comentar a diferença marcante entre os direitos e liberdades garantidos por lei e a sociedade real, Velho (1981, p. 146-148) defende que "a violência não pode ser reificada e vista como uma praga pairando sobre a sociedade. A violência existe ao nível das relações sociais e é parte constituinte da própria natureza desta sociedade cujo universo de representações não só expressa como produz a desigualdade e a diferença." Embora o autor esteja se referindo às instituições estatais em sua obrigação de garantir direitos, considero que suas reflexões podem iluminar a discussão sobre 0 jornalismo.
Em artigos de jornal publicados mais recentemente, 0 autor tende a minimizar ou pôr em segundo plano os possíveis impactos e contribuições da mídia para a disseminação e amplificação do medo (VELHO, 2002, p. 67, 85). ${ }^{19}$ Penso de forma diferente. Considerando a histórica dificuldade para se efetivar, consolidar e expandir a democracia no Brasil, os meios de comunicação corporativos contribuem decisivamente para a manutenção da desigualdade e para restringir 0 direito à fala a relativamente poucos atores sociais. ${ }^{20}$ 0 autor defende 0 aumento das instâncias e mecanismos de controle social sobre as instituições como condição sine qua non para se democratizar o país. Acredito que 0 princípio da necessidade de controle social deva estender-se também ao jornalismo e à publicidade - considerando, é claro, as notórias e óbvias diferenças entre estas áreas e as instituições estatais.

A postura do Jornal do Brasil no segundo dia de análise, longe de configurar um caso isolado, é típica da mídia corporativa nacional e deve ser enxergada à luz da "tradição da cultura política brasileira", a qual "não prima por valores universais como os direitos humanos nem cultiva critérios impessoais e

0 livro em questão reúne artigos publicados em diferentes jornais diários. Por um lado, não são científicos. Por outro, permitem ver claramente as posições do autor sobre a questão da violência - as quais evidentemente são per-meadas pelo lugar que ocupa na universidade e por seu olhar antropológico.

Isso sem mencionar a alimentação da discriminação, do ódio de classe e da desigualdade, ao não educarem para saídas por meio da construção de democracia e cidadania efetivamente igualitárias, soberanas e participativas etc. 
objetivos na vida profissional e na vida política" (BUCCI, 2000, p. 39). ${ }^{21}$

Como afirma o sociólogo Ignacio Cano, a cobertura da violência no Rio de Janeiro, embora diária e com amplo espaço na pauta jornalística, está fundada em episódios, e não no acompanhamento sistemático e discussão de questões macro e de fundo (apud FORTES, 2008; NJAINE et al., 1997). Ademais, existe um "caráter de classe da ética jornalística praticada no Brasil" (BUCCI, 2000, p. 157). Tal caráter permeia a cobertura jornalística em geral e, particularmente, a de assuntos como fofocas e vida íntima. Segundo Bucci (2000, p. 156-7), invasão de privacidade e possíveis danos à imagem de alguém só geram discussão quando este pertence à classe alta. É sintomática, neste ponto, a discussão levantada no jornalismo corporativo sobre 0 uso de algemas pela Polícia Federal na prisão de políticos e banqueiros famosos (e próximos aos interesses desta mesma mídia). Quando se trata dos pobres, a cobertura "não desperta a menor crise de consciência. [...] É como se nem mesmo o sensacionalismo mais barato pudesse prejudicar a imagem de alguém que, afinal de contas, nem goza do direito a ter uma reputação". ${ }^{22}$

\section{Juventude, estigmas e violência}

Misse [2003?] sugere que as classes populares "tendem a ser as que menos recorrem à polícia e à justiça e, ao mesmo tempo, a se tornarem o principal universo da desconfiança e da repressão policiais". Forma-se um ciclo em que justamente quem mais precisa do Estado para a garantia de direitos básicos - pois não tem outros mecanismos a acionar, como a contratação de serviços privados - é quem menos recorre a ele e quem se torna sua principal vítima. Por exemplo, a postura dos agentes do Estado responsáveis pelo registro é negligente quando as vítimas pertencem aos extratos mais pobres da população, 0 que "acaba por descaracterizar o evento violento". 0 descaso em relação às informações e à investigação é particularmente grande quando as vítimas são menores de idade (NJAINE et al., 1997, p. 410-11).

A representação social de quem não tenha recursos sociais para negociar com a polícia, mas mesmo assim a convoca - como ouvi muitas vezes no Rio - é que à denúncia se passe extra-judicialmente, na delegacia, à incriminação arbitrária do denunciado, transformando 0 denunciante em cúmplice não-intencional das práticas punitivas extra-judiciais que ali venham a se realizar [MISSE, 2003?].

A propósito, a pesquisa analisada por Pandolfi (1999, p. 49) revelou a tolerância e apoio a violações de direitos por parte de agentes do Estado, como a tortura de suspeitos. Sobre o peso relativo das relações pessoais no que diz res-peito à garantia de direitos e à atuação no espaço público, ver Matta (2000).

2 Uma das possíveis causas do fenômeno é a pouca representatividade de negros e jornalistas provenientes das classes populares nas redações da mídia corporativa. 
0 autor refere-se ao comportamento que muitas vezes se observa por parte de um braço Estado - a polícia - em relação a um setor específico (ainda que numeroso) da população: os pobres. Mas e se lançarmos mão de sua reflexão para iluminar o padrão de cobertura realizada pela mídia corporativa? Na situação específica em discussão, num primeiro plano, o jornal denuncia a existência de um crime praticado no Orkut, aproveitando as possibilidades de anonimato oferecidas pela internet. Nessa leitura, os mesmos agentes sociais praticam três ações: a) traficar drogas; b) posar para fotos exibindo seu poderio bélico; c) criar perfis no Orkut que fazem apologia ao tráfico de drogas através de textos e fotos. Mesmo considerando que os retratados naquelas fotos fossem traficantes, quem garante que foram os próprios que inseriram as imagens na internet com o objetivo de fazer apologia? Se não foram as mesmas pessoas, temos ações praticadas por diferentes agentes sociais, 0 " $\mathrm{a}$ " que trafica drogas e posa para fotos; e "b" que supostamente faz apologia do tráfico. Este último pode nunca ter traficado drogas, nem sequer visto pessoalmente uma arma ou droga - pode ser uma criança ou adolescente de classe média, dotada de computador, conhecimentos de informática e acesso à internet. ${ }^{23}$

Ocorre que, em uma cobertura jornalística que se caracteriza por repetir o mesmo tom a cada dia, dedica-se pouco ou nenhum espaço à reflexão, à desconfiança e ao contraditório. E se aquela foto tivesse sido feita numa festa à fantasia, ou numa brincadeira de adolescentes com armas de brinquedo ou na gravação de um filme? Novamente recorremos às reflexões de Misse sobre o processo social de incriminação

Quando a transgressão, cuja criminação é socialmente justificável, desliza para a subjetividade do transgressor e para sua individualidade, reificando-se socialmente como caráter ou enquadrando-o num tipo social negativo, constitui-se 0 que propomos chamar de sujeição criminal. Essa noção parece-me tanto mais interessante quanto maior for a capacidade do poder de definição de antecipar (ou prever) a adequação da incriminação a um indivíduo e de construi-lo como pertencente a um tipo social. Amplia-se a sujeição criminal como uma potencialidade de todos os indivíduos que possuam atributos próximos ou afins ao tipo social acusado [MISSE, 2003?].

A discussão do autor, como tenho frisado, diz respeito ao aparelho estatal. Mas suscita questões relativas à postura do Jornal do Brasil. Uma especulação: se houvesse (e talvez haja), no mesmo Orkut, fotos mostrando jovens de cabelo e olhos claros na mesma pose e local, teria ido parar na primeira página? Haveria algum estranhamento no processo de produção da notícia? A hipótese que levantamos é que houve verossimilhança no olhar lançado sobre aquelas imagens. Considerando o contexto (perfis do Orkut que fazem apologia ao crime) 
e 0 olhar hegemônico na sociedade, aqueles jovens, vestidos daquela forma, posando com aquelas armas e naquele local, se encaixam no papel aterrorizante atribuído aos traficantes de drogas. Esse olhar preconceituoso evidentemente não está presente apenas em jornalistas da mídia corporativa, mas sim em boa parte da sociedade, sobretudo nas classes média e alta que constituem a "opinião pública" para a qual falam veículos como $J B$ e $O$ Globo. Neste sentido, as reportagens em questão, baseadas em um grave erro, reforçam estigmas.

Apesar de todos os problemas, o processo jurídico de busca da verdade possui uma série de mecanismos para garantir a "neutralidade" [MISSE, 2003?]. A atribuição de determinar a ocorrência de um crime, ao cabo de um processo que geralmente começa por iniciativa dos atores sociais, é exclusiva do Estado. ${ }^{24}$

No entanto, os atores sociais nomeiam e representam inúmeros eventos como crime em antecipação retrospectiva, mesmo quando decidem não dar seguimento ao processo de criminação. Assim, uma 'criminalidade real' será oposta a uma criminalidade 'legal' ou 'aparente', aquela que foi reconhecida pelo Estado [MISSE, 2003?].
0 trecho permite pensar que a construção social da ideia de criminalidade vai muito além dos crimes efetivamente registrados e reconhecidos como tal. A sensação de insegurança e os sentimentos frente ao que é considerado um "crime" por alguém podem tanto ser guardados individualmente pela pessoa quanto contados a outras próximas a ela, sendo reproduzidos no lar, na família, no trabalho, no bate-papo na internet, na escola ou faculdade, no salão de beleza etc. ${ }^{25}$

A partir da citação, pode-se pensar o papel dos meios de comunicação, em especial do jornalismo, na divulgação de acontecimentos considerados "crimes". Independentemente de um ato vir a ser considerado um crime pelo Poder Judiciário, se noticiado como tal, o mesmo já terá sido entendido desta maneira pelos milhares (ou milhões) de leitores, ouvintes, ou telespectadores. Trata-se de um mecanismo poderosíssimo de amplificação de quaisquer acontecimentos (inclusive fictícios ou falsos). No caso da cobertura policial, a divulgação de crimes frequentemente tem pouco a ver com as estatísticas de ocorrência dos mesmos.

Três observações pontuais se fazem necessárias, pois, ao que parece, foram ignoradas pelo veículo no episódio: a) mesmo que os indivíduos estampados na primeira página do jornal tivessem sido acusados formalmente de tráfico de drogas e respondessem a processo jurídico, a condição de culpado só se configura após a sentença condenatória transitar em julgado (quando não cabe recurso). Entre os princípios estabelecidos para o andamento dos processos está o do direito do réu a ampla defesa; b) ademais, no caso em questão, a julgar pelas fotos, é provável que alguns dos atores fossem menores de idade (ver figura 1). A não identificação (preservação de identidade) constitui um dos direitos dos menores acusados de conflito com a lei. Curiosamente, este princípio foi observado na foto que consta na figura 4 (jovens com rostos cobertos por tarjas pretas), mas não pelo Jornal do Brasil (ver figura 1); c) as leis, em geral, existem para proteger. 
A princípio, a mídia corporativa segrega no plano simbólico. Mas a segregação tem efeitos tão concretos quanto deletérios no dia-a-dia da juventude pobre. Como afirmado antes, Caco Barcellos discutiu a legitimação das execuções policiais em São Paulo através dos jornais populares do tipo espreme e sai sangue. Ao publicarem a versão da polícia como o que de fato aconteceu, os impressos apresentam a versão de que tais mortes supostamente ocorreram em confronto - registradas como resistência seguida de morte - como verdade e transformam as vítimas (muitas delas sem passagem pela polícia) em criminosos.

De acordo com Velho (1994, p. 110):

As camadas pobres, os moradores de favelas, da periferia e dos subúrbios das cidades brasileiras estão sujeitos permanentemente a todos os tipos de arbitrariedades. Os assaltos, as batidas policiais, a ação dos 'esquadrões da morte' somam-se às dificuldades de trabalho, moradia, transporte, saúde etc. que constituem as condições de existência dessa população. As nossas 'boas pessoas', de um modo geral, só são sacudidas quando ocorre uma tragédia dentro de seu limitado in-group.

À lista de dificuldades enfrentadas pelos membros das camadas pobres acrescentamos a invisibilidade nos meios de comunicação corporativos, sintetizada na famosa frase "a dor do pobre não sai no jornal". 0 acesso à mídia é outra face da desigualdade. Quando as vítimas pertencem a famílias de classe média e alta - as quais, por sua vez, têm acesso à imprensa -, há indignação, artigos cobrando "providências" das autoridades, etc. Quase sempre reivindicase repressão por parte do Estado, mas não se procede a uma análise global do problema. Por outro lado, quando os envolvidos encontram-se nas camadas pobres, a mídia corporativa tende a ignorar o problema, contribuindo para o padrão de invisibilidade e indiferença em vigor:

É fascinante em termos sociológicos e chocante em termos éticos ver pessoas se deslocando dentro de uma sociedade injusta e violenta, anestesiadas diante da miséria, sofrimento e violência que afligem permanentemente os out-groups, no caso, a maioria esmagadora da população (VELHO, 1994, p. 111).

Como vimos argumentando, a violência simbólica - estigmatização ou invisibilidade promovidas pelos meios de comunicação hegemônicos tem consequências práticas: no Rio de Janeiro, por exemplo, diversas ações de segurança pública levadas a cabo pelo Estado respondem a demandas desses veículos.

0 estudo do antropólogo mexicano José Manuel

Valenzuela Arce contribui para o debate ao chamar a atenção para a construção social da imagem dos jovens. Além disso, como afirma o autor,

Quando a perturbação da segurança circunscreve-se aos bairros pobres, às favelas, às zonas populares, aos barracos, às cidades perdidas, aos cinturões de miséria, às universidades ou a alguma fábrica, sem afetar as rotinas de vida dos setores médios e altos, geralmente não são transtornadas as bases da habitabilidade, pois tal perturbação é proscrita ou exibida como traço distante que só ocorre nos locais habitados pelos pobres (ARCE, 1999, p. 59). 
Articulando esta discussão com a ótica sob a qual a suposta participação de traficantes no Orkut foi enquadrada pelo jornal, pode-se pensar nas matérias não apenas sob o ponto de vista da denúncia de um crime (apologia), mas da apreensão e construção do medo devido à aparição (invasão), naquele espaço, de jovens "ameaçadores" - como se não pudessem ser jovens de classe média e classe alta os que aparecem nas fotos e/ou os que as utilizam para fazer apologia. Segundo Arce, historicamente, "a ativação do jovem de classe média como ator emergente que caracterizaria a condição juvenil" colocou as representações de jovens de classes populares em segundo plano. Com isso,

As perspectivas dominantes estabeleceram que nas zonas e bairros populares havia delinquentes, desocupados ou trabalhadores, mas não movimentos juvenis. Isso nos mostra outra das dimensões da análise das representações dominantes sobre a juventude: sua condição seletiva (ARCE, 1999, p. 75).

A construção e consolidação deste olhar hegemônico se desenrola ao longo das últimas décadas, período em que praticamente inexistem projetos nacionais com propostas confiáveis para seus jovens [...] Ao que parece, deixouse para as indústrias culturais a definição das características adequadas do ser jovem. Formam-se modelos juvenis adequados aos modelos de consumo dos Estados Unidos e sataniza-se a grande maioria dos jovens latino-americanos excluídos dessas opções (ARCE, 1999, p. 84).

\section{A citação permite pensar as características a} que os jovens retratados nas fotografias foram imediatamente associados pelo jornal - mesmo tratando-se de pessoas que, via profissionalização, conseguiram escapar à sina e ao destino que muitos esperariam que cumprissem..$^{26}$ Neste ponto, fica clara a ligação entre 0 episódio analisado e o contexto histórico e social, que inclui, no caso brasileiro, um notável avanço da criminalização da pobreza ao longo desta década.

\section{Considerações finais}

Tais episódios não constituem exceção, mas rotina. A diferença é que, na maioria dos casos, a verdade não vem à tona e/ou não é divulgada no veículo que a violou. Uma das poucas ocasiões em que houve alguma discussão a respeito evidentemente insuficiente, inclusive pela não adoção de mecanismos concretos que pudessem evitar a repetição - foi o trágico e famoso Caso da Escola Base (RIBEIR0, 2000). Uma mudança neste quadro só é possível e viável nos marcos de uma redemocratização radical da mídia no Brasil, que traga pluralidade e garanta, através de regulamentação e pressão social, meios de comunicação a serviço do povo e com participação popular. 
Ainda que se considere que uma regulação maior deve incidir principalmente sobre as emissoras de rádio e televisão - concessões públicas cuja programação deve obedecer aos princípios e regras determinados pelos capítulos 220 a 224 da Constituição Federal -, os impressos não devem fugir ao compromisso com a legislação em vigor e 0 direito à informação. Esta "assume grande importância quando surge como um direito da sociedade e não como um produto de uso privado de instituições, sejam elas científicas, burocráticas, administrativas ou de comunicação" (NJAINE et al., 1997, p. 412). Informar mal, desinformar ou mentir, no quadro já degradado da segurança pública no Rio de Janeiro e com uma sociedade que tende a enxergar o problema através de uma série de estereótipos, significa reforçá-los.

Em termos metodológicos, é sempre complicado e temerário realizar análises a partir de um único caso. Contudo, devido ao caráter oligopólico dos mercados de comunicação, à propriedade cruzada, à falta de atuação do Estado para garantir o cumprimento da legislação vigente, não há razões para crer na existência de diferenças de fundo na cobertura realizada pelos diversos veículos e mídias em relação ao tema e ao acobertamento de erros.
A dificuldade para se garantir algo elementar - um jornalismo que fale a verdade - evidencia o quanto há por avançar na luta pelo direito à comunicação.

Contudo, caber ressaltar: há uma ampla, viva, rica produção autônoma fora dos oligopólios de mídia (ENNE, 2007; MORAES, 2009). Diversos veículos jornalísticos - fora da mídia corporativa - mostram que uma outra comunicação social é possível. Com frequência, faltam-lhes condições de sobreviver, crescer e ganhar visibilidade. Diferentemente do que ocorre na mídia corporativa, neles é possível encontrar algumas das dezenas de temas essenciais para o futuro do país que seguem sendo discutidos nos legislativos, executivos e judiciários, nas ruas, nos movimentos sociais, nos bares, nos sindicatos etc. Sobre tudo isso, por parte da mídia corporativa, poucas palavras, pouco destaque, pouca discussão democrática.

Talvez a única - e triste - ironia do episódio resida no fato de jovens que se envolveram com as artes e nelas encontraram um caminho profissional terem sido condenados por um veículo da mesma mídia que vive celebrando a aproximação com artes e esporte como panaceia para as crianças e adolescentes de comunidades pobres. ${ }^{27}$ Salvos pela arte, por vias tortas acabaram condenados, na mídia, ao mesmo destino do qual haviam se livrado. Mesmo quando escapam do

A defesa de tais soluções vincula-se quase sempre a trabalho voluntário e ONGs - cuja atuação, vale lembrar, é necessariamente seletiva e de forma alguma garante a concretização dos direitos de crianças, adolescentes e jovens moradores de comunidades pobres. Tal postura, a meu ver, constitui uma das faces da "nova pedagogia da hegemo-nia, [a qual] propõese a estimular um tipo de participação que [...] tenta incentivar movimentos caracterizados por soluções individuais" (NEVES; SANT'ANNA, 2005, p. 35). 
"destino inexorável", a sociedade encontra formas de lhes devolver ao lugar que espera que ocupem.

\section{Referências bibliográficas}

ARBEX JÚNIOR, José. Uma outra comunicação é possível (e necessária). In: MORAES, Dênis de (org.). Por uma outra comunicação: mídia, mundialização cultural e poder. Rio de Janeiro: Record, 2003. p. 385-400.

ARCE, José Manuel Valenzuela. Vida de barro duro: cultura popular juvenil e grafite. Rio de Janeiro: UFRJ, 1999.

ATHAYDE, Celso; BILL, MV; SOARES, Luiz Eduardo. Cabeça de Porco. Rio de Janeiro: Objetiva, 2005.

BUCCI, Eugênio. Sobre ética e imprensa. São Paulo: Companhia das Letras, 2000.

CONSTITUIÇÃO da República Federativa do Brasil, sítio de legislação do Senado Federal. Disponível em: <http://www.senado.gov.br/sf/legislacao/const/con1988/ CON1988_11.11.2009/art_5_.htm>. Acesso em: 20 nov 2009.

CORDEIR0, Tiago. Matéria do JB confunde atores com traficantes. Comunique-se, 15 maio 2007. Disponível em: <http://www.comunique-se.com.br/index. asp?p=Conteudo/NewsShow.asp\&p2=idnot\%3D36384\% 26Editoria\%3D8\%260p2\%3D1\%260p3\%3D0\%26pid\%3D 164737225\%26fnt\%3Dfntnl>. Acesso em: 3 maio 2009.

ENNE, Ana Lúcia S. "0 jornalismo está morto, viva o jornalismo!": reflexões sobre usos e práticas de comunicação. Contracampo, Niterói, v. 16, p. 71-92, 1. sem. 2007.

FERNANDES, Fernando Lannes. Os discursos sobre as favelas e os limites ao direito à cidade. Cidades (Grupo de Estudos Urbanos), Presidente Prudente, v. 2, n. 3, p. 37-62, jan-jun 2005. Disponível em: <http://www. observatoriodefavelas.org.br/noticias_antigas/arquivos_ noticias/File/0s discursos sobre as favelas e os limites ao direito cidade.pdf $>$. Acesso em: 20 jun 2009.
FONTES, Virgínia. Intelectuais e mídia - quem dita a pauta?. In: COUTINHO, Eduardo Granja (org.).

Comunicação e contra-hegemonia: processos culturais e comunicacionais de contestação, pressão e resistência. Rio de Janeiro: Ed. UFRJ, 2008. p. 145-61. FORTES, Rafael (org.). Segurança pública, direitos humanos e violência. Rio de Janeiro: Multifoco, 2008. FORTES, Rafael. Condenados pela primeira página. A Lenda, 15 maio 2007a. Disponível em: <http:// rafaelfortes.wordpress.com/2007/05/15/condenadospela-primeira-pagina>. Acesso em: 3 jun 2009. Condenados pela primeira página II. $A$ Lenda,16 maio 2007b. Disponível em: <http:// rafaelfortes.wordpress.com/2007/05/16/condenadospela-primeira-pagina-ii $>$.

Acesso em: 3 jun 2009. Condenados pela primeira página III. $A$ Lenda, 22 jun 2007c. Disponível em: $<$ http://rafaelfortes.wordpress.com/2007/06/22/ condenados-pela-primeira-pagina-iii>.

Acesso em: 3 jun 2009.

GINZBURG, Carlo. 0 extermínio dos judeus e 0 princípio da realidade. In: MALERBA, Jurandir (org.). A história escrita: teoria e história da historiografia.

São Paulo: Contexto, 2008. p. 211-32.

MARTÍN-BARBER0, Jesús. Novas visibilidades políticas da cidade e visualidades narrativas da violência. In: COUTINHO, Eduardo Granja (org.).

Comunicação e contra-hegemonia: processos culturais e comunicacionais de contestação, pressão e resistência. Rio de Janeiro: UFRJ, 2008. p. 11-26.

MATTA, Roberto da. A casa \& a rua: espaço, cidadania, mulher e morte no Brasil. 6. ed. Rio de Janeiro: Rocco, 2000.

MISSE, Michel. Sobre a construção social do crime no Brasil: esboços de uma interpretação. [2003?]. Sítio do Núcleo de Estudos da Cidadania, Conflito e Violência Urbana (NECVU/IFCS/UFRJ). Disponível em: 
$<$ http://www.necvu.ifcs.ufrj.br/arquivos/Sobre\%20a\%20 constru\%C3\%A7\%C3\%A30\%20social\%20do\%20crime\%20 no\%20Bra\%5B1\%5D.pdf>. Acesso em: 18 dez. 2007.

MORAES, Dênis de. Outros jornalismos, outra comunicação. IHU On-Line, São Leopoldo, n. 289, p. 21-23, 13 abr 2009.

NEVES, Lúcia Maria Wanderley Neves; SANT'ANNA, Ronaldo. Introdução: Gramsci, o Estado educador e a nova pedagogia da hegemonia. In: NEVES, Lúcia Maria Wanderley (org.). A nova pedagogia da hegemonia: estratégias do capital para educar o consenso. São Paulo: Xamã, 2005. p. 19-39.

NJAINE, Kathie et al. A produção da (des) informação sobre violência: análise de uma prática discriminatória. Cadernos de Saúde Pública, Rio de Janeiro, v. 13, n. 3, p. 405-14, jul-set 1997. Disponível em <http://www.scielosp.org/pdf/csp/v13n3/0165. pdf>. Acesso em 20 jun. 2009.

PANDOLFI, Dulce Chaves. Percepção dos direitos e participação social. In: et al. (org).

Cidadania, justiça e violência. Rio de Janeiro: FGV, 1999. p. 45-58.

PRAZERES, Michelle. MP investiga contrato do governo de SP com Editora Abril. Observatório da Imprensa, 28 abr. 2009. Disponível em: < http:// observatorio.ultimosegundo.ig.com.br/artigos. asp?cod=535CID001>. Acesso em: 9 mai 2009. REVOGAÇÃO total da Lei de Imprensa ameaça a democracia. Intervozes, 5 mai 2009. Disponível em: $<$ http://www.intervozes.org.br/sala-de-imprensa/ agenda/5-de-maio-de-2009-revogacao-total-da-lei-deimprensa-ameca-a-democracia> . Acesso em: 9 maio 2009.

RIBEIR0, Alex. Caso Escola Base: os abusos da imprensa. São Paulo: Ática, 2000.

RONSINI, Veneza Mayora. Fluxo midiático e cultura juvenil. In: XIII ECONTRO ANUAL DA COMPÓS, 2004, São Bernardo do Campo. Anais... São Bernardo do Campo: Compós, 2004, p. 1-20.
VELHO, Gilberto. Individualismo e cultura: notas para uma antropologia da sociedade contemporânea. Rio de Janeiro: Zahar, 1981.

Projeto e metamorfose: antropologia das sociedades complexas. Rio de Janeiro: Jorge Zahar, 1994.

Mudança, crise e violência: política e cultura no Brasil contemporâneo. Rio de Janeiro: Civilização Brasileira, 2002. 


\section{Convicted by front page: discussing relations between journalism, ethics and truth}

\section{Abstract}

Among the different types of media production, journalism products - which establish an apparent link with truth - hold an outstanding power, social insertion and acceptance. From a broad concern with Brazilian corporate media agenda (FONTES, 2008), this communication focuses on a case study: a front page piece of "news" from Jornal do Brasil (15 may 2007) informing that drug dealers were using Orkut - a social networking web site - to promote and show off criminal activities. Nevertheless, the following day, "it was found out" that, in fact, the teenagers who appeared on the photographs were actors participating in the production of a police film. Far from being an isolated episode, the case is typical and helps to illuminate some aspects related to production routines and editorial lines of corporate media, such as the fact that the newspaper did not admit at all that it had lied. This paper also approaches the ethic and political implications of certain postures adopted by such journalism.

\section{Keywords}

Journalism. Ethics. Jornal do Brasil. Youth. Violence.

\section{Condenados por la primera página: discutiendo sobre las relaciones entre periodismo, ética y verdad}

\section{Resumen}

Entre los tipos producción de media, el periodismo que establece, en teoría, un vínculo con la verdad tiene un poder excepcional y cuenta con grande inserción y aceptación social. Desde un debate sobre el contenido de la agenda de los medios de comunicación de Brasil (FONTES, 2008), este artículo examina un episodio: la "noticia" en la primera página de Jornal do Brasil (15 mayo 2007) informando que los traficantes de drogas estaban utilizando el sitio internet Orkut para hacer apología de la delincuencia y mostrar sus armas. Sin embargo, al día siguiente, "fue descubierto" que, de hecho, los jóvenes que aparecieron en las fotografías eran actores que participaban de la producción de una película policial. Lejos de ser un caso aislado, el incidente es típico y ayuda a arrojar luz sobre los aspectos de las rutinas de producción y la línea editorial de los medios de comunicación corporativos, como el hecho de que en ningún momento el periódico ha reconocido que "mintió". El trabajo también aborda las implicaciones éticas y políticas de estas posturas adoptadas por el periodismo.

\section{Palabras clave}

Periodismo. Ética. Jornal do Brasil. Juventud. Violencia. 


\section{Expediente}

A revista E-Compós é a publicação científica em formato eletrônico da Associação Nacional dos Programas de Pós-Graduação em Comunicação (Compós). Lançada em 2004, tem como principal finalidade difundir a produção acadêmica de pesquisadores da área de Comunicação, inseridos em instituições do Brasil e do exterior.
E-COMPÓS I www.e-compos.org.br I E-ISSN 1808-2599

Revista da Associação Nacional dos Programas de Pós-Graduação em Comunicação. Brasília, v.13, n.1, jan./abr. 2010.

A identificação das edições, a partir de 2008 passa a ser volume anual com três números.

\section{CONSELHO EDITORIAL}

Afonso Albuquerque

Universidade Federal Fluminense, Brasil

Alberto Carlos Augusto Klein

Universidade Estadual de Londrina, Brasil

Alex Fernando Teixeira Primo

Universidade Federal do Rio Grande do Sul, Brasil

Alfredo Vizeu

Universidade Federal de Pernambuco, Brasil

Ana Carolina Damboriarena Escosteguy

Pontifícia Universidade Católica do Rio Grande do Sul, Brasil

Ana Silvia Lopes Davi Médola

Universidade Estadual Paulista, Brasil

André Luiz Martins Lemos

Universidade Federal da Bahia, Brasil

Ângela Freire Prysthon

Universidade Federal de Pernambuco, Brasil

Antônio Fausto Neto

Universidade do Vale do Rio dos Sinos, Brasil

Antonio Carlos Hohlfeldt

Pontifícia Universidade Católica do Rio Grande do Sul, Brasil

Arlindo Ribeiro Machado

Universidade de São Paulo, Brasil

César Geraldo Guimarães

Universidade Federal de Minas Gerais, Brasil

Cristiane Freitas Gutfreind

Pontifícia Universidade Católica do Rio Grande do Sul, Brasil

Denilson Lopes

Universidade Federal do Rio de Janeiro, Brasil

Eduardo Peñuela Cañizal

Universidade Paulista, Brasil

Erick Felinto de Oliveira

Universidade do Estado do Rio de Janeiro, Brasil

Francisco Menezes Martins

Universidade Tuiuti do Paraná, Brasil

Gelson Santana

Universidade Anhembi/Morumbi, Brasil

Goiamérico Felício

Universidade Federal de Goiás, Brasil

Hector Ospina

Universidad de Manizales, Colômbia

Herom Vargas

Universidade Municipal de São Caetano do Sul, Brasil

leda Tucherman

Universidade Federal do Rio de Janeiro, Brasil

Itania Maria Mota Gomes

Universidade Federal da Bahia, Brasil

Janice Caiafa

Universidade Federal do Rio de Janeiro, Brasil

Jeder Silveira Janotti Junior

Universidade Federal da Bahia, Brasil
João Freire Filho

Universidade Federal do Rio de Janeiro, Brasil

John DH Downing

University of Texas at Austin, Estados Unidos

José Luiz Aidar Prado

Pontifícia Universidade Católica de São Paulo, Brasil

José Luiz Warren Jardim Gomes Braga

Universidade do Vale do Rio dos Sinos, Brasil

Juremir Machado da Silva

Pontifícia Universidade Católica do Rio Grande do Sul, Brasil

Lorraine Leu

University of Bristol, Grã-Bretanha

Luiz Claudio Martino

Universidade de Brasília, Brasil

Maria Immacolata Vassallo de Lopes

Universidade de São Paulo, Brasil

Maria Lucia Santaella

Pontifícia Universidade Católica de São Paulo, Brasil

Mauro Pereira Porto

Tulane University, Estados Unidos

Muniz Sodre de Araujo Cabra

Universidade Federal do Rio de Janeiro, Brasil

Nilda Aparecida Jacks

Universidade Federal do Rio Grande do Sul, Brasil

Paulo Roberto Gibaldi Vaz

Universidade Federal do Rio de Janeiro, Brasil

Renato Cordeiro Gomes

Pontifícia Universidade Católica do Rio de Janeiro, Brasil

Ronaldo George Helal

Universidade do Estado do Rio de Janeiro, Brasil

Rosana de Lima Soares

Universidade de São Paulo, Brasil

Rossana Reguillo

Instituto Tecnológico y de Estudios Superiores do Occidente, México

Rousiley Celi Moreira Maia

Universidade Federal de Minas Gerais, Brasil

Samuel Paiva

Universidade Federal de São Carlos, Brasil

Sebastião Albano

Universidade Federal do Rio Grande do Norte, Brasil

Sebastião Carlos de Morais Squirra

Universidade Metodista de São Paulo, Brasil

Simone Maria Andrade Pereira de Sá

Universidade Federal Fluminense, Brasil

Suzete Venturelli

Universidade de Brasília, Brasil

Valério Cruz Brittos

Universidade do Vale do Rio dos Sinos, Brasil

Veneza Mayora Ronsini

Universidade Federal de Santa Maria, Brasil

Vera Regina Veiga França

Universidade Federal de Minas Gerais, Brasil

\section{COMISSÃO EDITORIAL}

Felipe da Costa Trotta I Universidade Federal de Pernambuco, Brasil Rose Melo Rocha I Escola Superior de Propaganda e Marketing, Brasil CONSULTORES AD HOC

João Maia I Universidade do Estado do Rio de Janeiro, Brasil Sandra Gonçalves I Universidade Federal do Rio Grande do Sul, Brasil Mayra Rodrigues Gomes I Universidade de São Paulo, Brasil Gisela Castro I Escola Superior de Propaganda e Marketing, Brasil João Carrascoza I Escola Superior de Propaganda e Marketing, Brasil Luciana Pellin Mielniczuk I Universidade Federal de Santa Maria, Brasil Irene de Araújo Machado I Universidade de São Paulo, Brasil Hermilio Pereira dos Santos Filho I Pontifícia Universidade Católica, Brasil Benjamim Picado I Universidade Federal Fluminense, Brasil Maria Apaecida Baccega I Escola Superior de Propaganda e Marketing, Brasil Rogério Ferraraz I Universidade Anhembi Morumbi, Brasil

Bruno Souza Leal I Universidade Federal de Minas Gerais, Brasi REVISÃO DE TEXTO E TRADUÇÃo I Everton Cardoso EDITORAÇ̃̃ ELETRÔNICA I Roka Estúdio
COMPóS I www.compos.org.br

Associação Nacional dos Programas de Pós-Graduação em Comunicação

Presidente

Itania Maria Mota Gomes

Universidade Federal da Bahia, Brasil

itania@ufba.br

Vice-presidente

Julio Pinto

Pontifícia Universidade Católica de Minas Gerais, Brasil juliopinto@pucminas.br

Secretária-Geral

Ana Carolina Escosteguy

Pontifícia Universidade Católica do Rio Grande do Sul, Brasil carolad@pucrs.br 